\title{
Conceptualising the lessons-learned process in project management: Towards a triple-loop learning framework
}

\author{
Sue McClory, Martin Read \& Ashraf Labib \\ Portsmouth Business School, University of Portsmouth
}

\begin{abstract}
In order to improve success rates of project management, this conceptual paper proposes the inclusion of knowledge management and organisational learning through projects as core aspects of the process, from both individual and organisational perspectives. The lessons-learned process within the project management profession is scrutinised in an attempt to provide new models to overcome the difficulties that inhibit success. Empirical research data from 66 practitioners in an online qualitative survey have influenced the development of our conceptual model. We review single- and double-loop learning systems within the organisation environment, and develop a triple-loop of learning for projects that forms the basis of a new framework. This research will enable future development of processes for utilising the lessons-learned throughout the project life-cycle and the organisation.
\end{abstract}

Keywords: Project success and strategy; Developing organisational maturity; Knowledge management

\section{Introduction and background}

Flyvbjerg (2014) notes that over a 70-year period project cost overruns remain high, often exacerbated by benefit shortfalls of between 20\% and 50\%. But Project Management (PM) success can no longer be determined only by the 'iron triangle' measures of time cost and quality, as Williams (2016) noted that both research and practice are moving towards 
multi-dimensional definitions involving objective and subjective criteria. However, as Rolstadas, Tommelein, Morten Schiefloe, and Ballard (2014, p. 656) concluded:

"The recipe to PM success has yet to be found, and there will probably be no single best solution. Success depends on many factors that may shift from project to project and from organisation to organisation".

Our research question examines: "How improvements in the lessons-learned process can increase project success and develop organisational learning”.

The lessons-learned process is intended to capture the results and experiences from successes, failures, and near-misses, and absorb them in to the organisational structure for future use. However, although lessons are often identified their capture and categorisation face problems of both available time and process, while their application in future projects appears limited. Meredith and Mantel (2010) determine the project manager's role as one of learning from their own and others' experience, utilising lessons-learned for early warning signs (EWS) and for pretested remedies. First in the list of fundamental causes of project failure being "no use of earlier project final reports that contained recommendations for future projects" (Meredith and Mantel, 2010, p. 558).

Many organisations only partially engage in the lessons-learned process, allocating a project manager's time and investing money in a database, but gaining little or no visible benefit. There is limited guidance in the Bodies of Knowledge (BoKs) or PM handbooks on the implementation of a lessons-learned process, but several successful organisations that have invested in the cultural and processual aspects, generate a return on their investment.

This paper aims to identify issues surrounding the lessons-learned process and offer a framework for putting knowledge management and organisational learning together as a core process within the whole life of the PM activity - from planning through to closing 
reports. This unique combination will enable the capture and application of lessons to be recognised and managed as benefits to both project and organisation. By preventing recurrence of problems, project-based organisations can make significant savings in their future projects against the traditional measures of time, cost and quality.

Project managers require a consistent organisation-wide database to enable the retrieval of relevant lessons. Such systems typically face two problems: the integration of new knowledge with existing, and the removal of obsolete knowledge from the database (Wijnhoven, 2003). Knowledge management systems require maintenance to prevent their falling into disuse due to obsolete information, or through the lack of context around information which leads to misinterpretation (Hasan and Crawford, 2003). However, experience of developing expert systems and intranets for knowledge management has shown that people underestimate the complexity of such a project (Wijnhoven, 2003).

This paper focuses on the project process and its situation within the organisation, by conceptually representing it as a triple learning loop, developed from the work of Argyris and Schön (1996) in the field of organisational learning. The contribution to knowledge provides a firm platform from which to develop a framework to integrate the lessonslearned process into the parent organisation through a range of procedures, to provide the necessary learning management modules for the BoK.

The remainder of the paper is organised as follows: section 2, current professional guidance, and section 3, literature review. Section 4 provides the definitions of knowledge and learning, and section 5 organisational and individual learning. Section 6 determines the project learning requirements to enable the empirical data collection and analysis process for section 7. Then a lessons-learned framework is presented in section 8 with project represented conceptually in sections 9,10 and 11 , as single-, double- and triple- 
loop learning activities, respectively. Section 12, contains discussion of the project learning framework and in section 13 future developments are examined.

\section{Current professional guidance}

Professional institutes recommend establishing a knowledge bank that centralises information gained by individual project managers, as it enables the passing of information between projects. All PM professionals work on a three-stage process to maintain a lessons-learned knowledge bank by:

- accessing previous lessons during project planning and delivery phases,

- keeping project logs to record lessons throughout the project duration, and

- writing lessons-learned reports both during project and at project closure.

Williams (2003) observed that, in practice, project review processes were rarely in place, project success and failure was rarely analysed, and suggested that learning did not happen. The Association for Project Management (APM) includes the following relevant key actions in its BoK to be undertaken during and after a project (Association for Project Management, 2012):

- preparation and dissemination of lessons-learned to be defined in the communications management plan,

- storage of the information to be clearly defined in key documents to ensure classification and accessibility to data,

- post-project review to be part of the project control process, and

- audit trails for archived information to provide additional support for lessonslearned documents. 
The Project Management Institute (PMI) BoK includes the lessons-learned document as a requirement at the closure point of any phase or project (Project Management Institute, 2013). There is also a requirement for a 'corporate knowledge base' for storing and retrieving all project documentation including lessons-learned. The lessons-learned documents are referred to as inputs to or outputs from many of the project processes in the detailed activities throughout the PM process. Likewise, the PRINCE2 framework (Office of Government Commerce, 2009) includes the same principles as the BoKs for the threestage process detailed above. The APM identifies the lesson-learning process as a key indicating factor of organisational maturity and part of professional development (Association for Project Management, 2012), while the PMI includes the updating of organisational procedures and policies with the lessons-learned process (Project Management Institute, 2013). Despite the clear guidelines, there are contradictory views regarding the use of the lessons-learned process in projects, and the identification of aspects causing the difficulties.

Recent studies have indicated where some of the problems lie: knowledge transfer and learning occur through social and situated learning, and de-coupling the lessons-learned process significantly reduces their value (Hartmann and Dorée, 2015); six individual elements must be in place for the lessons-learned knowledge model to work - learning, culture, social activities, technology, process and infrastructure (Duffield and Whitty, 2015). While these studies point towards the requirements for a learning focus within PM, the lessons-learned process is not yet situated within the project organisation in a theoretical framework from which to implement as a practical process.

Irani (2010) posits whether success really exists and, if everything else is just a degree of failure. There are many definitions of project success and PM success, but the APM 
recognise the following high-level success factors as main contributors to PM success (Association for Project Management, 2012, p. 32):

- "Defining clear goals and objectives

- Maintaining a focus on business value

- Implementing a proper governance structure

- Ensuring senior management commitment

- Providing timely and clear communication”

While PM success can include wide-ranging criteria including timescales beyond project close or delivery, the APM factors enable a focus on the PM activities.

\section{Literature review}

The temporary nature of projects, whose focus is on the short-term goals of the project, creates a barrier to learning within the organisation and disrupts the knowledge flow (Bartsch et al., 2013). When the project team disperse project knowledge is fragmented, without creating organisational routines or memory, whereas departments and divisions of permanent organisations act as knowledge silos (Lindner and Wald, 2011).

One approach to avoiding project underperformance or failure is to detect EWS in order to be able to take the necessary corrective action (Haji-Kazemi et al., 2013). However, project risk and elements of uncertainty create a difficult environment to identify weak EWS (Klakegg et al., 2010), and cultural barriers - including a high level of optimism, a lack of open culture to discuss project difficulties, and political issues - affect their discussion (Haji-Kazemi et al., 2015).

It is acknowledged in the literature that both organisations and individuals tend to learn more from failures than from success (Labib and Read, 2013), and that failures contain 
valuable information; however, organizations vary in their ability to learn from them (Desai, 2008). The negative nature of episodes in learning (i.e. learning from failure) is likely to produce a different unit of analysis and a different type of research output than if learning is from a positive experience (i.e. learning from success; Eden and Huxham, 2001). Much of the literature on learning from success or failure is based on the non-project environment. Other studies (Goffin et al, 2010; Jugdev and Wishart, 2014) identified that access to tacit knowledge was necessary, suggesting enablers for capturing and disseminating lessons, and promoting the social aspects of sharing. The social problems can become learning barriers, especially where projects separate departments of an organisation (Bartsch et al., 2013).

Research by Duffield and Whitty (2015) focussed on the organisational issue of people and systems required in order for lessons to be applied and implemented. Their literature review determined that lessons were often identified and captured, with much of the information transferred successfully; however, the application aspect was the problem. They determined that the following six individual elements needed to be successful, in order for the lessons-learned knowledge model to work: learning, culture, social activities, technology, process and infrastructure. While their paper identifies the requisites for a successful lessons-learned process, it fails to address the particular problems faced by project-based organisations. Hartmann and Dorée (2015) compared the formal process of recording and using lessons-learned against a social process through five project case studies. They concluded that lessons-learned need to be connected through social and project activities, and that de-coupling them from the project significantly reduced their value. They considered the formal process was of a 'send/receive' style that created many barriers to the effective use of lessons-learned. However, this is too simplistic, as the 'send/receive' style Hartmann and Dorée refer to is the process of using a lessons-learned 
database for depositing and withdrawing knowledge, and utilised in the proper manner this can provide useful information for project discussions.

Problems identified with the practical operation of a knowledge database are now being addressed. Jessop et al. (2016) used a pattern language to enable lessons to be structured in terms of issues, contextual relevance, forces at work, solution, new context and additional background information. Each of the patterns received a contextual name (e.g., role clarity or integrating design teams) and reference number to allow cross-referencing. Their study recommended the use of experts and advisors to help create the initial database from the lessons already gathered, which would eliminate much of the duplication from post-project reports. The number of occurrences of each issue would assist the team in defining common problems. However, research into knowledge transfer between concurrent projects determined that it was not the relation between the sender and receiver, but the recipients' ability to absorb the information that was relevant (Zhao et al., 2015). Bakker et al. (2011) determined that it was the responsibility of the parent organisation not the project manager, to ensure that knowledge was valued and utilised, and that a high level of absorptive capacity was required for success.

\section{Defining knowledge and learning}

"Knowledge is what we perceive to be real and true" (Johnson, 2000).

"Learning is a relatively permanent change in behaviour due to experience" (Walker, 2006).

Knowledge, as defined above, is subjective and depends upon an individual's perception and social context. Therefore it could be assumed that organisational knowledge contained in company files as regulations, policies, records of actions and decisions, maps, 
or physical objects - is subject to the individual's or team's perception during the formation and update process of those artefacts.

The APM BoK defines knowledge management as the process of converting personal information and experience in to collective knowledge, through the systematic management of information and learning, which enables it to be shared throughout the organisation (Association for Project Management, 2012). It highlights the need to capture knowledge and experience in order to improve decision-making, whilst acknowledging that the format of recording lessons-learned often makes it difficult for others to use. Key steps for successful knowledge management include ownership and responsibility for the operation and structure of the system to be used, in addition to the process of extracting lessons-learned from projects complete with their contextual detail. Its use can reduce risks and increase efficiency, although it is accepted that assembly of knowledge can be difficult, and creating an environment where it is valued and used is frequently problematic. Within the project life-cycle, the documentation of lessons-learned at project closure is viewed as a key indicating factor of organisational maturity. As a professional body, the APM encourages project organisations to develop their maturity and engage in Communities of Practice (CoPs), whether inside their organisation, their industry, or across sectors. The PMI BoK refers to the 'Corporate Knowledge Base' which contains all the files from previous projects, financial databases, configuration management, issues and defect control information, and additionally the lessons-learned knowledge bases and their associated historical information (Project Management Institute, 2013).

The project organisation is considered a holding environment for knowledge (Argyris and Schön, 1996); when this knowledge is held as individual attributes, it may be lost to the organisation when that person leaves. Although, as each individual contributes towards the informal working practices, these can remain embedded within the organisation. Learning Page 9 
systems within the PM environment must identify the individual attributes that enhance working practice to formalise the process of informal learning, if possible. These individual attributes of skill and experience are considered as tacit knowledge - and without this, explicit knowledge loses its meaning (Nonaka et al., 2000). It is deeply rooted within the individual's action and experience, as well as in the ideals, values, or emotions they embrace. Nonaka and Takeuchi (1995) refer to the two dimensions of tacit knowledge the skills or craft experience, plus the cognitive dimension of schemata, mental models and perceptions. The Japanese refer to new ideas as 'knowledge creation' which converts tacit knowledge to explicit knowledge through:

- Metaphor - putting known things together in new ways, and

- Analogy - distinguishing two ideas through 'compare and contrast' methods.

Many studies have defined the stages of knowledge management, with several variations and different terms used. The following list includes Ranjbarfard, Aghdasi, López-Sáez, and Emilio Navas López (2014) thorough review of previous work, combined with other studies (Algeo, 2014; Wijnhoven, 2003) to provide a summary of the knowledge process:

- Generation - also called creation, production and development. New knowledge gained by innovation, experimentation, creative thinking, or acquisition.

- Storage - the selective retention of existing, acquired and created knowledge consisting of information, documents and experiments, in a properly indexed knowledge repository with search and retrieval functions.

- Transfer - also called sharing, integration, distribution and dissemination. The spreading of existing knowledge within the organisation, between a source and recipient. Methods include teaching, searching and social activities. 
- Application - or utilisation. Retrieving and using knowledge to support decisions, actions, problem-solving and training. Activities to ensure that existing knowledge is productively applied.

The Organisation Knowledge Loop (Figure 1) demonstrates the organisational knowledge retained as artefacts that create formal routines, individual knowledge attributes that provide the informal practices, and how new knowledge is stored. This combines the interrelated factors that previous models show in isolation. The process of knowledge transfer between the individual, the organisation, and the repository is a complex mixture of cultural and organisational processes.

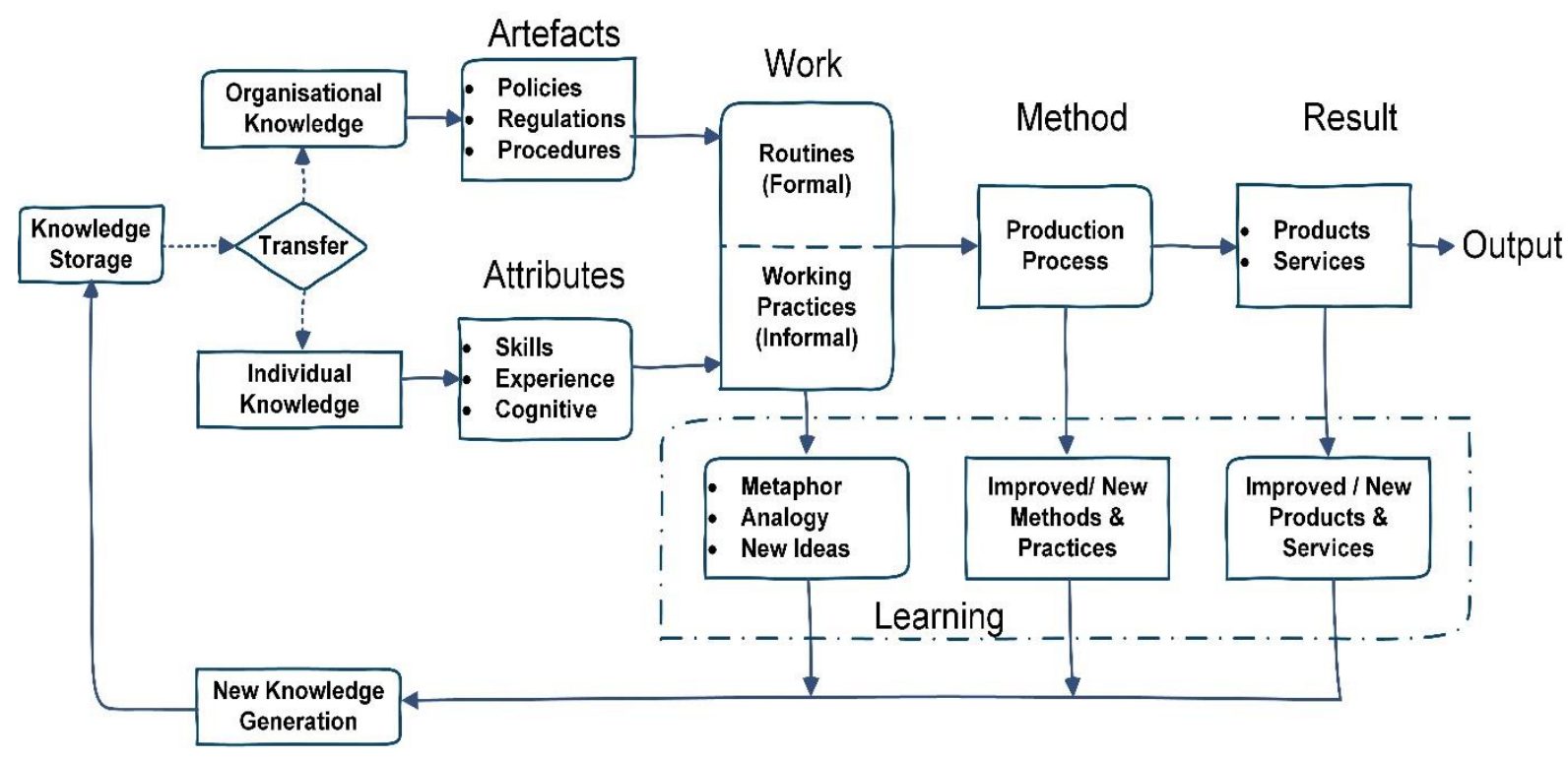

Figure 1: The Organisational Knowledge Loop.

Research by Preskill and Torres (1999) determined the situations where individual, team and organisational learning could occur through evaluative enquiry. Interestingly, these are not processes, tools or artefacts, but the cultural and social environment established - the values behind the organisation: a focus on current issues, challenging assumptions, reflecting and valuing past experience, information-based enquiry within a climate of trust and honest communication to ensure a valid process for planning and decision-making. 
Organisational learning is stored within the knowledge bank through its artefacts, but in order to be realised, it must be accompanied by individual learning which is only evident through a change of behaviour. Learning can be demonstrated when formal work routines are updated from the testing and development of knowledge, and these are followed by changes in work practices (i.e. behaviour). Learning can occur under two conditions (Argyris, 1999, p. 67):

- "When an organisation achieves what is intended; that is, there is a match between the design for action and the actuality or outcome.

- When there is a mismatch between the intention and the outcome, which is identified and corrected; that is, a mismatch is turned into a match."

We must consider how organisations and individuals respond to these two conditions, what preparations they have made for each, and how they value the resulting data. When a mismatch occurs for an individual, this can create cognitive dissonance unless the situation is carefully handled. Support for a required behaviour change is vital to maintain staff morale. Dewey (2005) defined learning as a continuous reorganisation and reconstruction of experience. He advocated learning through experimentation and practice, not through memorisation and recitation of information. We determine that a learning organisation, undertakes risk analysis to determine its vulnerability and prepare for unplanned events; it also develops action plans for future learning based on its experiences. We now analyse organisational and individual learning in more detail.

\section{Organisational and individual learning}

An organisation is a group of individuals working together for a common purpose through a structured system. It could be deduced that when an individual learns something, the organisation has also, by association, learnt; that the collective learning resides within the 
body of the organisation. Conversely it could be argued that individual knowledge does not enter distinctive organisational thought and action, therefore the organisation knows less than its members (Argyris and Schön, 1996). Organisations do not perform the actions that produce the learning - it is the individuals who produce the behaviour that leads to learning (Argyris, 1999). However, it is the organisation that creates the conditions that influence how the individual perceives the problem, designs the solution, and produces the action to solve the problem (Argyris, 1999). These conditions are controlled to a greater or lesser extent by the organisation through processes and procedures, the cultural and political environment, recent experiences, and the value placed on learning by management.

An individual brings biases and constraints to the learning situation which are relatively independent from the organisation's requirements (Argyris, 1999). Each individual has a limited capability for processing information, and a learning capacity; they also bring their personal methods and standards to a team which can influence the learning approach. These elements of human nature and organisational politics often inhibit the learning process when we look for scapegoats, use control games, systemic patterns of deception, hide true intentions, or maintain taboos (Argyris and Schön, 1996).

A repeated exposure to stressors generates a toughening process to provide endurance (Lepore and Revenson, 2006), and a learning organisation will remain vigilant for EWS and include the process for change within its operational procedures. Organisations that do not react early enough, or ignore smaller failures, are not in a position to cope with larger problems when they occur because they do not have the systems in place to implement changes to procedures or behaviour - they are not learning organisations. We shall now examine the requirements for successful organisational learning. 
The five standardised levels of maturity models, adopted by both academics and institutes, is fully aligned with the Capability Maturity Model Integration of 1993 (Langston \& Ghanbaripour, 2016, p. 70):

- 'Initial: processes are unpredictable, poorly controlled and reactive

- Repeatable: processes are characterised for projects and are often reactive

- Defined: processes are characterised for the organisation and are proactive

- Managed: processes are measured and controlled

- Optimising: there is a focus on process improvement"

The maturity level of learning within an organisation depends upon the readiness and willingness of both the individual and the organisation to question expectations, values, experiences and actions (Probst and Buchel, 1997). The additional tools of the Probst and Buchel model provide useful maturity factors that are measured across three dimensions:

- Knowledge - the level of learning instruments (formal and informal)

- Ability - level of ability to learn (questioning, analysis of action, communication)

- Intention - level of willingness to learn (led by the organisation, but an understanding of why learning is important by individuals and groups)

The term learning organisation demonstrates that the goal of learning covers every aspect of the company; from governance and ethics of the management, and the cooperative culture of employees, through to the storage and access of knowledge and support for learning throughout the organisation. Senge (2006) proposed five interrelated personal disciplines required to become a learning organisation (the term discipline meaning a path of development for acquiring particular skills or competencies, to be studied, mastered, and put into practice): 
- Personal mastery - the discipline of continually clarifying and deepening our personal vision, focusing energy, developing patience and seeing reality objectively.

- Mental models - an ability to describe and discuss our internal pictures of the organisation, to enable open thinking and influence with others.

- Building shared vision - gaining a commitment to work towards the organisational goal(s).

- Team learning - where the combined output of the team exceeds that of the individuals. This produces extraordinary results, and rapid growth of individuals.

- Systems thinking - the four previous disciplines work together to create the necessary mind shift to become a learning organisation. To discover how people create their reality, and how they can change it.

“These five disciplines might as well be called leadership disciplines" - (Caldwell, 2012, p. 41). Caldwell's (2012) critical examination of Senge's principles suggests the work is flawed due to a lack of theories for organisational practices by which leading-learning concepts are shared or distributed within the organisation. He concludes that the work neglects issues of practice and issues of power, in that leaders would require the power and knowledge to define the learning and control the storage and transfer of knowledge, setting or steering the direction of learning for the organisation. "Senge's learning organisation is primarily a reconfigured top-down leadership theory of systemic organisational change, rather than a theory of agency, change and learning in organisations" (Caldwell, 2012, p. 42). Fillion et al. (2015) note that most organisations following Senge's five disciplines apply the practice rules, principles and values in only one or two of the disciplines. To become a learning organisation, they determine, it is necessary to implement all five Senge 
disciplines and recommend two additional concepts - knowledge generation and sharing, and organisational behaviour (Fillion et al., 2015).

Huber's (1991) framework proposes that organisational learning contains four processes:

- Knowledge acquisition - congenital, experiential, vicarious, grafting-on, searching and noticing

- Information distribution - sharing of information from a wide range of sources to enable creation of new information or understanding

- Information interpretation - through cognitive maps and framing, but also considering conditions of overload, and unlearning

- Organisational memory - storage and retrieval system supported by technology processes

Crossan, Lane and White (1999) undertook a review of Senge, Huber, and Nonaka and Takeuchi models among others, concluding that despite some developing multi-level frameworks none address how one level affected another. They note the following shortcomings:

- Senge - processes focus on the individual and the group, and is not a levels-related model.

- Huber - takes an information processing perspective. Processes are within levels, but no model or process linking those levels.

- Nonaka and Takeuchi - concentration on product innovation. Focusses on processes that link the individual and group, but weak on links between the group and organisation levels. 
Crossan et al. (1999) propose their own model 'The 4I' to overcome the shortcomings of other models resulting in a multi-level framework across individual, group and organisation. Feed-forward and feedback processes work across the levels, with 'interpreting' and 'integrating' becoming the bridges. The 4Is consist of:

- Intuiting - perceiving patterns and possibilities at the individual level

- Interpreting - explaining one's insight to others through a variety of methods (bridging individual and group levels)

- Integrating - developing a shared understanding and taking coordinated action through mutual adjustment (bridging group and organisation level)

- Institutionalising - embedding the learning of individuals and groups into the organisation through its systems, structures, procedures and strategy.

The feed-forward aspect assimilates new learning, helping new ideas and actions to flow from the individual to the group, while the feedback aspect exploits or uses what has already been learned from the organisation to the group and individual levels (Crossan et al., 1999). This model relies on good communication at the individual and group level to enable articulation of tacit knowledge, but the main tension exists between the feedback mechanism possibly destroying new ideas and insight travelling in the forward direction (Crossan et al., 1999). Recent studies (Williams, 2016) on project success factors indicate that company culture is key, led by the senior management team, operating in a climate of 'no blame' with personal improvement plans for employees and the formation of 'learning teams'; Ika and Donnelly (2017, p. 59) determine that "high levels of multi-stakeholder commitment, collaboration, alignment and adaptation were not only likely to be present, but are in fact necessary for a project to be considered a success". 
The literature review has identified learning issues for both the individual and organisation, and reviewed the relationship of knowledge management to learning in context of outcome analysis and decision making based on results. These must now be tested against the practice within the current PM industry, to identify where the barriers are within the lessons-learned process.

\section{Project learning requirements}

The authors developed the Organisational Knowledge Loop (Figure 1) to demonstrate relations between the knowledge management process, individual and organisation from perspectives of culture and organisational process. In section 5 Argyris (1999) determined the issues of the individual and the organisation, while Crossan et al. (1999) discussed the multi-level issues of the individual, group and organisation, and how links are required between each of these. Of particular interest is the Probst and Buchel (1997) model that includes the formal and informal learning, requirements for communication and a learning culture, and the necessity for the organisation to lead learning while supporting group and individual levels. Huber's (1991) framework highlights knowledge acquisition, information distribution, interpretation, and organisational memory requirements. Bringing these aspects together, the knowledge loop and measures of organisational maturity (Probst and Buchel, 1997) are set against the Duffield and Whitty (2015) six categories of organisational requirements for lessons-learned (Table 1).

Table 1: Summary of Project Learning, Organisational Knowledge and Learning Maturity.

\begin{tabular}{|c|c|c|}
\hline $\begin{array}{c}\text { Duffield and Whitty, 2015 } \\
\text { Requirements for project } \\
\text { learning }\end{array}$ & $\begin{array}{c}\text { Organisational Knowledge } \\
\text { Loops }\end{array}$ & $\begin{array}{c}\text { Probst and Buchel, 1997 } \\
\text { Maturity of a Learning } \\
\text { Organisation }\end{array}$ \\
\hline $\begin{array}{c}\text { Learning } \\
\text { Qualifications, experience, } \\
\text { skills }\end{array}$ & $\begin{array}{c}\text { Individual attributes, } \\
\text { organisational \& individual } \\
\text { knowledge }\end{array}$ & $\begin{array}{c}\text { Knowledge Measures } \\
\text { Formal and informal learning } \\
\text { instruments }\end{array}$ \\
\hline
\end{tabular}




\begin{tabular}{|c|c|c|}
\hline Values, belief, passion & $\begin{array}{l}\text { Examination of routines, } \\
\text { work practices, production } \\
\text { processes and outputs }\end{array}$ & $\begin{array}{c}\frac{\text { Ability Measures }}{\text { Culture of questioning and }} \\
\text { analysis }\end{array}$ \\
\hline 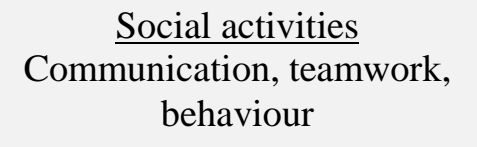 & $\begin{array}{l}\text { Exploration of new ideas } \\
\text { through metaphor, analogy } \\
\text { and problem solving }\end{array}$ & $\frac{\text { Ability Measures }}{\text { Communication }}$ \\
\hline$\frac{\text { Technology }}{\text { Equipment and software }}$ & $\begin{array}{l}\text { Knowledge storage and } \\
\text { transfer system }\end{array}$ & $\begin{array}{l}\text { Intention Measures } \\
\text { Does the organisation have } \\
\text { the willingness to learn }\end{array}$ \\
\hline $\begin{array}{l}\underline{\text { Process }} \\
\text { Planning, running and closing } \\
\text { stages of a project }\end{array}$ & $\begin{array}{l}\text { Examination of practices, } \\
\text { processes and outputs, } \\
\text { blended with new ideas }\end{array}$ & $\begin{array}{l}\text { Knowledge Measures } \\
\text { Formal learning instruments }\end{array}$ \\
\hline $\begin{array}{c}\text { Infrastructure } \\
\text { Support from PMO, } \\
\text { Communities of Practice }\end{array}$ & $\begin{array}{l}\text { Knowledge generation, } \\
\text { development, storage and } \\
\text { transfer }\end{array}$ & $\begin{array}{c}\text { Intention Measures } \\
\text { Organisational will to learn } \\
\frac{\text { Knowledge Measures }}{\text { Informal learning }} \\
\text { instruments }\end{array}$ \\
\hline
\end{tabular}

To create links between organisational levels, the single- and double-loop learning is reviewed and developed. Hall (1993, p. 278) disaggregated the concept of social learning, and determined that policymaking involved three central variables, which he referred to as 'orders' of learning:

- "Third order - the overarching goals that guide the policy in a particular theme

- Second order - the techniques or policy instruments used to attain those goals

- First order - the precise settings of those instruments"

Argyris (1999, p. 68) defines single-loop learning as: "an error is detected and corrected without questioning or altering the underlying values of the system". Fillion et al. (2015) refer to this as adaptive learning where, observing from a single perspective, individuals adapt to the work to be performed.

Argyris (1999, p. 68) defines double-loop learning as: "mismatches are corrected by first examining and altering the governing variables, and then reviewing the actions". Fillion Page 19 
et al. (2015) refer to this as generative learning where, observing from multiple perspectives, continuous learning and improvement of creative potential, develops the ability to reach the objectives. Fillion et al. (2015) add that sometimes both adaptive and generative learning are assimilated into single-loop learning. No clear definition is agreed for single- and double-loop learning, whether the move from individual to collective learning makes an additional loop, or whether it results from moving from behaviour adjustment to a changing of rules, is unclear. Moving from a change of rules to a change of hypothesis results in a higher order of learning, either single- to double-loop, or doubleto triple-loop, also called deutero learning. Indeed, it is noted that literature on the learning organisation is limited to a small number of researchers (Fillion et al., 2015).

There are several conceptualisations of triple-loop learning developed from Argyris and Schön's work on double-loop learning (Tosey et al., 2012), the most significant being Bateson. His levels of learning operate concentrically to indicate a widening scope that incorporates previous levels (Bateson, 2000), and function through a multi-level process of interdependent factors and feedback loops (Bredo, 1989). Fillion et al. (2015) refer to triple-loop learning as transforming and creative learning where the following questions from the work of Isaacs (1993, p. 30) require an answer:

- "What is driving me and others to be predisposed to learn in this way?

- Why these objectives?"

Developing the triple-loop learning concept, with the items from Table 1, a framework is created for the lessons-learned process within the organisational setting (Figure 2). This research aims to determine the barriers and enablers for the lessons-learned process and develop the organisational knowledge loop to incorporate practices and processes, the 
technical and social aspects of the knowledge storage and transfer system, and the cultural issues of communication, questioning, and willingness to learn.

\section{Data collection and analysis}

Interview data with project professionals and trainers, generated by a closely related research project, enabled the outline work for constructing the survey instrument. Questions are mapped to the lessons-learned process (Figure 2) to finalise the survey design. Primary data collected anonymously from practicing project managers, mostly working in the UK, were obtained through professional project groups on LinkedIn. Official groups for APM and PMI have more than 240,000 members between them, but we also included another 10 PM groups (e.g. The Project Manager Network, Project Manager Community and PMO). We invited 350 group members to participate in a 30min qualitative on-line survey, 66 of whom fully completed the questions which form the dataset for this phase of research.

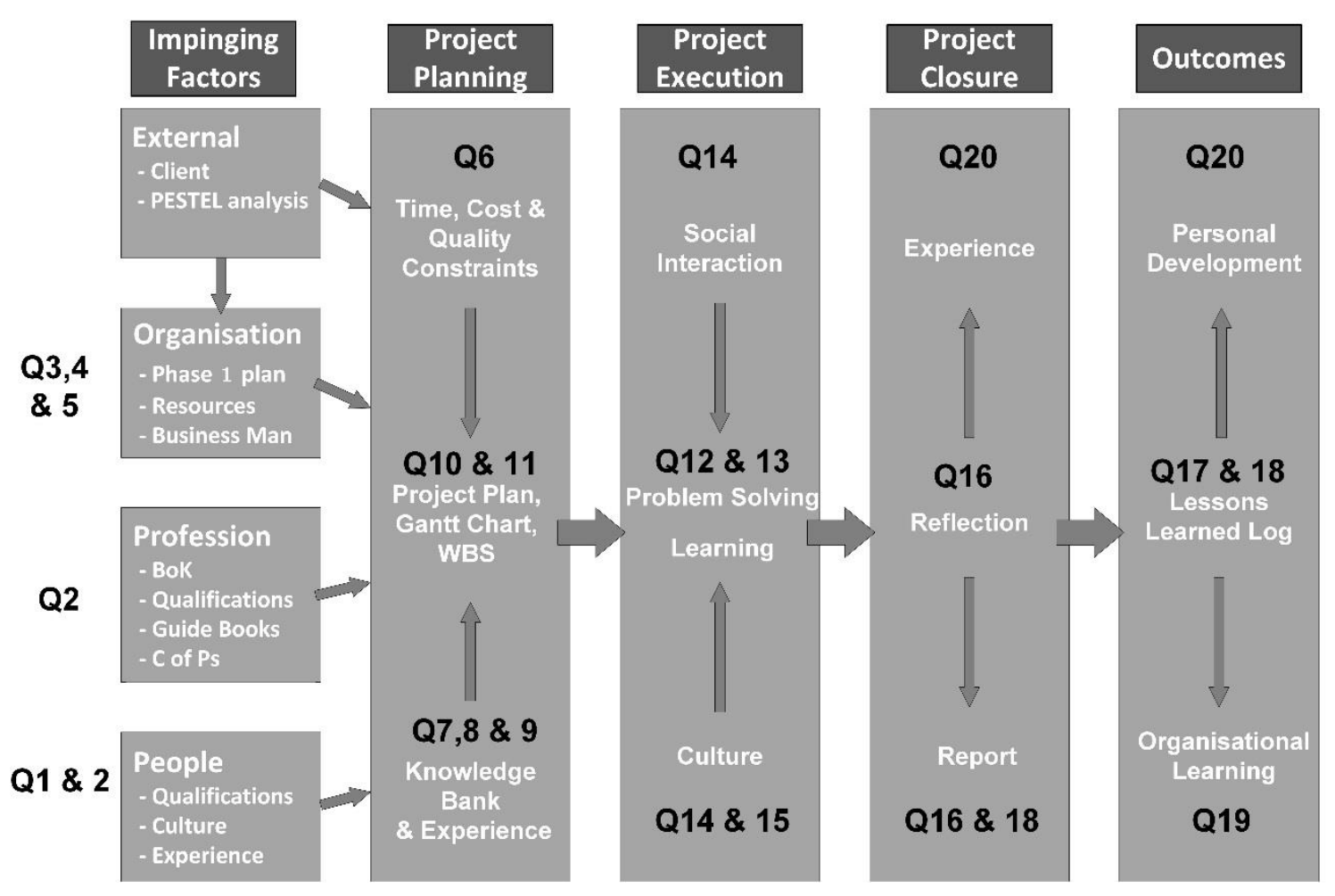


Figure 2: The Survey Design.

Questions 1 and 2 determine respondents' qualifications and years of experience, while questions 3 to 5 identify the organisational structure, PMO functions and the PM methodology in use. The respondents consist mainly of experienced project managers $9 \%$ with five years or less experience, $26 \%$ between six and fifteen years, $30 \%$ between sixteen and twenty-five years, and $26 \%$ with more than twenty-five years' experience. Almost all participants possess PM qualifications (APM, PMI, IPMA, PRINCE2, MBA or MSc), some with more than one professional body; three engineers have recently taken a PM qualification, while only three respondents hold no formal PM qualification. Types of organisation the respondents work for reveal $44 \%$ operating within a matrix structure, $26 \%$ each for functional and PBOs, with $4 \%$ as contractors who have covered a variety of organisation types.

Question 6 provides opportunity for project managers to identify typical project problems encountered. Questions 7 to 20 cover the planning, delivery and closure phases of project learning; respondents are asked about accessing previous lessons-learned (LL), recording lessons and writing closure reports, at the personal, project and organisational levels. A brief summary is shown in Table 2. The survey requests description and explanation of processes in use, providing large comment boxes for replies. Question 21 allows additional comments on the LL process to ensure all relevant data are captured.

Table 2: Summary of on-line survey questions.

\begin{tabular}{|l|l|l|}
\hline \multicolumn{1}{|c|}{ Planning } & \multicolumn{1}{|c|}{ Delivery } & Closure \\
\hline Q7. What is the process & $\begin{array}{l}\text { Q12. How are lessons } \\
\text { accessed }\end{array}$ & $\begin{array}{l}\text { Q16. How do you conduct } \\
\text { review }\end{array}$ \\
\hline Q8. Type of lesson gained & $\begin{array}{l}\text { Q13. How do you record } \\
\text { lessons }\end{array}$ & $\begin{array}{l}\text { Q17. Categorisation of } \\
\text { lessons }\end{array}$ \\
\hline
\end{tabular}




\begin{tabular}{|l|l|l|}
\hline $\begin{array}{l}\text { Q9. Your experience or } \\
\text { others }\end{array}$ & Q14. How often & $\begin{array}{l}\text { Q18. What happens to the } \\
\text { report }\end{array}$ \\
\hline $\begin{array}{l}\text { Q10. Sufficient context } \\
\text { Q11. Discussed with team }\end{array}$ & $\begin{array}{l}\text { Q15. What barriers or } \\
\text { enablers exist }\end{array}$ & Q19. Organisational benefit \\
\hline & $\begin{array}{l}\text { Q20. Individual \& team } \\
\text { learning }\end{array}$ \\
\hline
\end{tabular}

Responses downloaded from the on-line provider in Excel spreadsheet format, enabled statistical analysis of the personal data from questions 1 to 5 . All data responses were uploaded to NVivo11 qualitative analysis software and coded to 30 open codes. Selective coding aligned categories with those of the Duffield and Whitty (2015) Syllk Model, while an 'external' category covered items outside the organisation, and data were also coded to 'success' or 'failure' attributes.

When asked about accessing lessons from previous projects during the planning stage, $42 \%$ of respondents stated there is either no system in place or the system is not used. However, some retained personal registers - for example, one respondent said "We don't have access to this as an organisation, only what our own team records and that isn't done properly. (i.e., people just make their own lists and save them)". Many rely on their own previous experience, or that of their project team for drawing on previous lessons - for example "Previous Project Experience 9 times out of 10 because I suspect I won't gain much at all from the Organisational database. I will always seek out a discussion with project managers in an organisation for their personal tips - it is a worry that this can be useful where the Lessons KM system usually isn't!!"

Those companies that operate a LL knowledge bank have varying degrees of success - for example "It could be improved by using a set format, one used across the organisation rather than individual departments and teams 'doing their own thing'", "It was process to hold LL reviews throughout the project, but when it came to the end of the project the 
outcome didn't go anywhere because nobody managed it and reviewed all of the outcomes", "Usually collected at the end of a project rather than throughout the project", or the system not fully utilised "We use an online database where lessons learnt should be logged and used by all. However, this database is not embedded into the project environment and as such is not used to its full potential", "Lessons are captured but there is no real impact for new projects".

Some companies' knowledge banks of LL are not being utilised - "Little review of lessons learned from the company knowledge bank, generally because finding relevant data in the bank is so difficult"; "It's very hard to search and find what is needed, we find personal contact with SME's and assessors better". While other organisations have alternative methods for sharing project knowledge, for example "The ability to use a static database or knowledge bank is quite an ineffective way of sharing project knowledge. Complex projects are often riddled with difficulties and challenges and required face to face discussion with previous manager. Thus in our business we encourage sharing of project experiences through regularly briefing of projects to the wider community to help people learn and ask questions as we go. It does require a culture of sharing and willing to learn".

Some organisations have a fully mandated process - "Active project sponsorship from line manager of project manager regarding what is required and expected in the initialisation phase of a project: - 1. Project Manager expected to obtain the lessons learned reports/presentation material from the business systems (review and reflect into their baseline, management approach etc. - 2. Expected to speak to project managers who worked in similar projects to seek out their experiences and advice. - 3. Gate review (with experienced individual) to test project strategy and advise wider stakeholders (who project manager may not know or aware of). Expected to complete actions before progressing”, while others do not - "We have a Learning from Experience programme; the problem is 
that we are very good at capturing lessons, but not so good at learning from them. People learn from their own lessons; and we benefit from other people's experience through independent gate reviews, but people don't tend to access lessons learned reports".

Project managers are accessing items from the LL database during their projects for a variety of reasons, sometimes triggered by the project - "Accessed when encountering new risks, issues assumptions \& dependencies”, or by the need to comply with process requirements - "Stage gate process", "lessons learnt database and it is a key element of our review process to demonstrate lessons learnt". At other times project managers benefit from the experience of other staff - "Via individuals who experienced them sharing as part of team or as sponsor advice. Multiple triggers (often late!)”, "Coaching from PMO team. Triggered if the project is of sufficient importance to come to the attention of the PMO”, "Generally through engagement with individuals who 'bare the scars' from previous projects in the assurance process. This will normally be triggered by the formal review process". The recording of LL during the run of the project is often reported as a regular activity, weekly, fortnightly, monthly or at stage gates. Respondents suggested several improvements to the process through standardisation - "It could be improved by using a set format, one used across the organisation rather than individual departments and teams 'doing their own thing'", having the support of senior managers "I think it's just seen as a 'tick in the box' exercise. If people see that these are being used in earnest then I'm sure they will engage in the process more. Invariably, the senior managers need to be insisting on reviewing LL's and seen to take action where the business are constantly doing things incorrectly or the wrong way. In a nutshell, take notice of where things need to improve and take action to remedy, and be seen to do it", or by utilising a LL 'champion' - "Having a person to be a lessons learned champion with the authority to make things happen would be a significant advantage. - Purchasing and supporting a suitable database 
to record the lessons, priority, actions, owners and dates - Allocating resource, time and budget to implement agreed changes - People believe there is never the time to make the changes and without senior management buy in there is little appetite to address the change - Blame cultures exist in some organizations". Communication is seen as important - "We have daily catch-ups, where issues can be raised, so long as there is good communication then this can be captured early on and actioned soon enough too", "We try to embody everything in tools and databases but there are many barriers such as culture and nobody has time to write the reports or read them".

Recording LL at project closure takes several forms - "We review using post-its on the wall (what went well and what didn't) - we then triage these where there are common postits - then everyone gets a set number of votes to discuss in more depth, and determine action points to get through the issues in the future", "As LL captured and updated week by week through project delivery in weekly project report the project closure report is quite easy now to generate - Team emailed report and asked to comment on a conference call about this matter", while one organisation left it to the project manager alone "The Project Manager completes it based on his/her experiences - The team is not involved".

When asked if their database is set up with categories 15 respondents said theirs was not, for example - "No - it would but is thought not to be sufficient to justify the effort", "No but it would be a good idea for them to be"; while 26 respondents said their LL database was categorised through a variety of methods - "Clarification is essential to understand what the issue was and why it occurred (both positive and negative lessons) - Classification into groups (coding, requirements, testing etc.) allows greater focusing and search ability is essential", "Lessons are clarified according to their likelihood of happening, their cost and schedule impacts, and their safety implications. This helps greatly”. 
There is a clear requirement for a mandated process for managing project knowledge as depicted in Figure 1, with data results correlated against Table 1 columns of 'Duffield and Whitty' and 'Organisational Knowledge Loop'. However, the maturity measures of these items are complex problems, given that many of the project learning processes are not fully in place for the majority of PBOs.

\section{Lessons-learned framework}

We now represent the LL process as single-, double- and triple-loops from the literature to enable the capture and re-use of lessons between projects, for information and decisions on learning to pass between levels, and identify where supporting roles are required.

\section{Single-loop project learning}

The measurement of project progress is long-established with a variety of methods to compare time, cost and quality against targets set within the project plan. Visualised in Figure 3, the project is managed at 1, with outcomes measured (2) at project milestones, gates or regular time intervals. Outcome evaluation occurs (3) where LL are recorded throughout the project duration by daily and weekly logs, and a closing project report. Comparison of outcome against project parameters allows decisions to be taken (4) to determine required action to bring the project back on track (5). Single-loop project learning adjusts the project action or underlying assumptions to meet targets as much as possible while leaving the project parameters unchanged. This process is necessary to track project progress, provide accurate forecasts for cash-flow and staff allocation for resource managers, and keep stakeholders abreast of important changes or issues.

Many respondents identified a lack of skilled PM staff, and not having a standard PM methodology across their organisation, the 14 comments include - "Projects are not 
managed properly, even though outcome might be considered successful and deliverables met. So in this case it is the management not the project that has a problem", "People barriers are that people in our project teams often do not understand what we are doing (including myself, which led to higher education in project management). There needs to be more effort to standardise project management across the organisation", "Almost everybody claims that he/she does project management", "Poor understanding of Project Control Methodologies, due to lack of training", and "Most project leads are primarily technical leads with variable PM skills”.

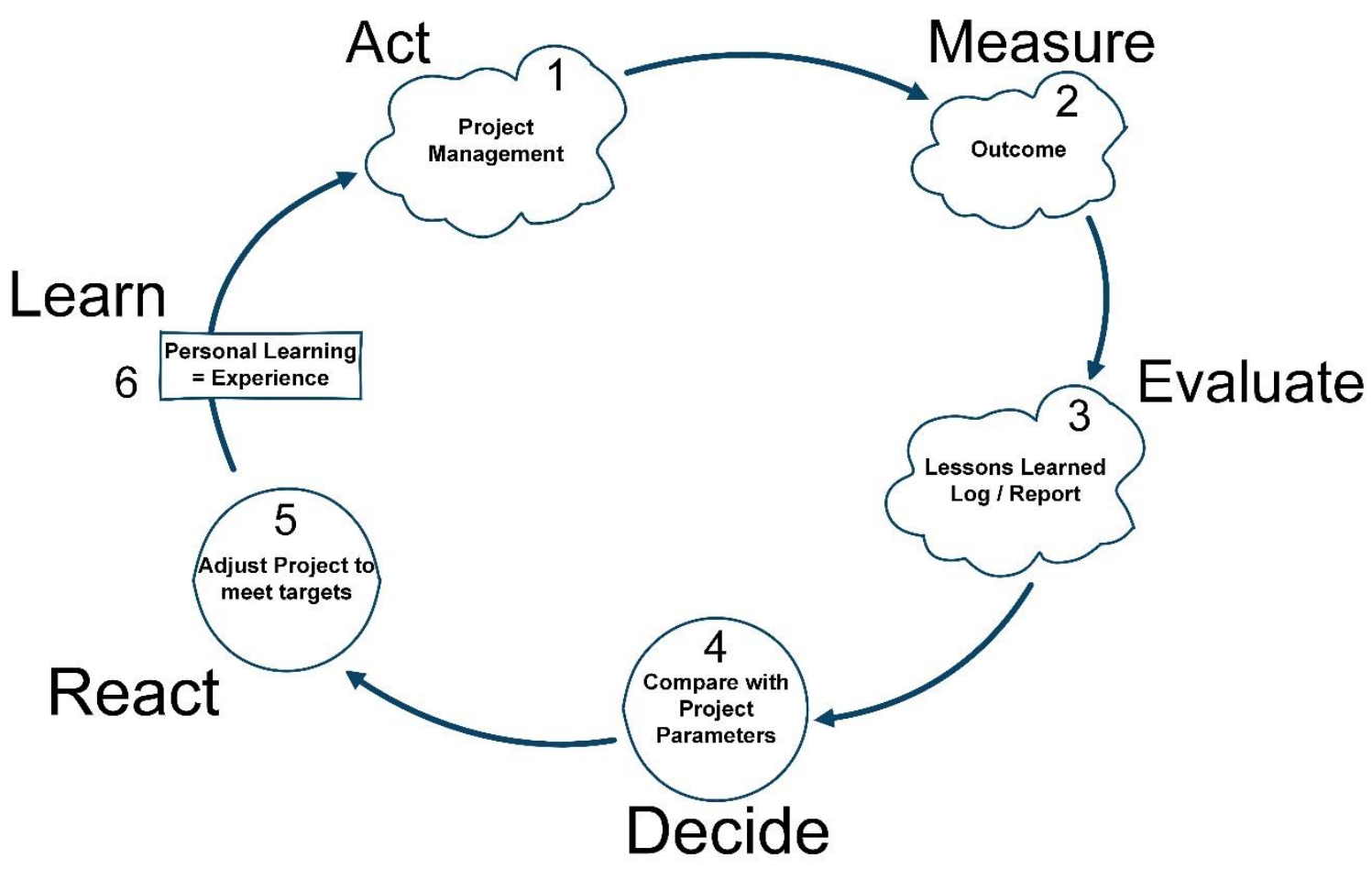

Figure 3: Single-Loop Project Learning.

Project managers learn much of their skill through this experience of measuring project output, making adjustments and re-running the loop. It provides that personal level of learning which creates experience (6, above). The process continues looping for every period of measurement determined in the project plan, culminating in the closing report. 


\section{Double-loop project learning}

The governing variables in PM terms fall into two distinct groups - those which define the parameters of the specific project, and those which define the governance of projects in general within the parent organisation. In double-loop learning the evaluation step (Figure 4) is broadened to analyse both measured outcome and the value against which it is measured. Decisions taken now include the assessment of processes and parameters to ensure these fulfil the higher level goals of both the project and organisation. Action is taken to change project-level parameters and update organisations policies where necessary. However, the adjustment of parameters must be undertaken carefully otherwise it can result in poor decision-making and a failure to learn the right lessons from the data. For example, the phrase 'normalization of deviance' defined the process through which data outside the limits was subsequently reinterpreted as being within normal limits by increasing those limits (Vaughan, 1996).

Not only does double-loop learning operate at both project and organisational levels, but is necessarily concurrent with single-loop learning. When project parameters are changed, the project requires re-assessment of the measured outcomes against the updated parameter values; Argyris and Schön (1996) refer to the zones of ambiguity between single and double-loop learning, which become complicated by organisational size and project complexity. This is where the underlying assumptions determined for the project come in to play, they are neither measured values nor governing variables, but their value can affect the outcome of either, or both, of these data sets.

Learning within the double-loop operates at project level instead of personal, where learning is then embedded within organisational processes. As with single-loop learning 
the process continues looping as determined in the project plan, culminating in the closing report.

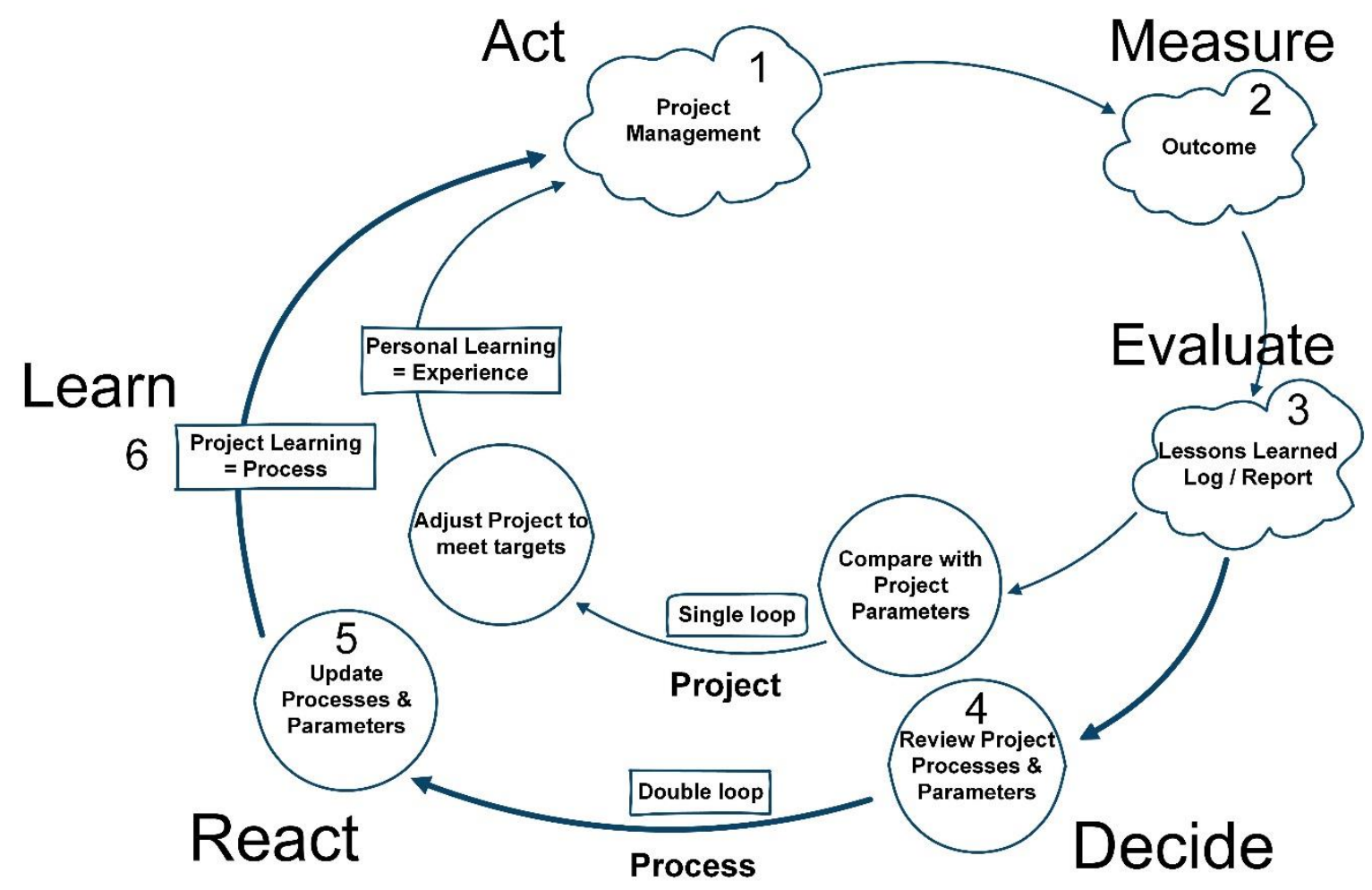

Figure 4: Double-Loop Project Learning.

To achieve the status of a learning organisation, we develop a third loop - to learn about the learning. This requires the organisation to achieve a high level of learning maturity across the Knowledge, Ability and Intention criteria defined previously.

\section{Triple-loop project learning}

The third learning loop in this paper includes the organisation's cultural values and goals in terms of a learning organisation. The evaluation step (Figure 5) provides the Project Management Office (PMO) with its role definitions - at project level performance data, closing reports and LL logs are gathered for review and reporting; at process level project targets are revised with sponsors and procedures updated if required; while at 
organisational level learning action plans for new projects are generated and information passed to board-level. Practitioners identified problems in the relationship between the project team and those further up the management chain, either project sponsors or those with a governance responsibility. The 19 comments include weaknesses in oversight of projects, and a lack of senior management support - "Sponsors unsure of their role on a project", "Project sponsors are too hands off and don't help resolve risks/major issues",

“Weak sponsorship”, and "Lack of governance and decision making”.

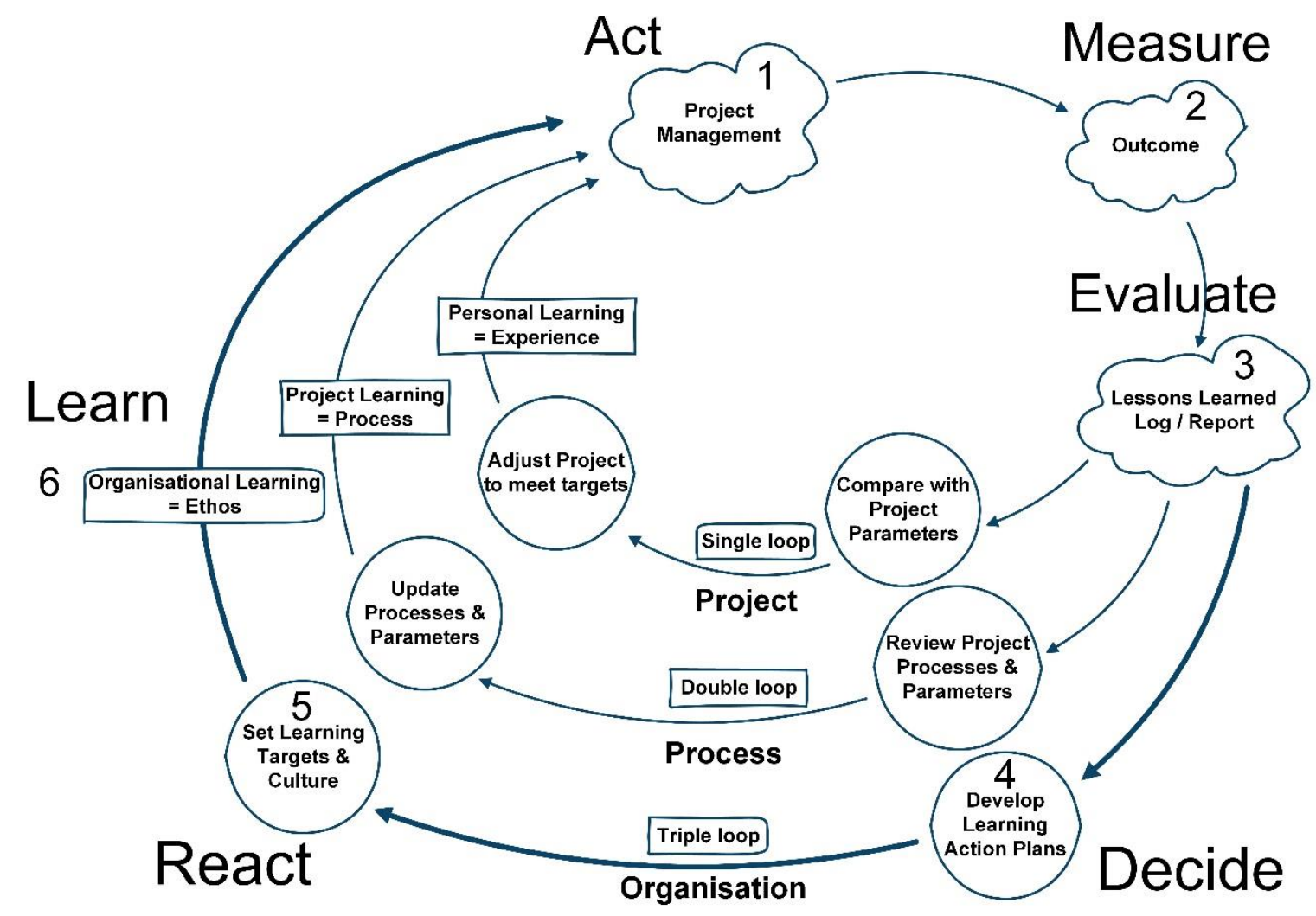

Figure 5: Triple-Loop Project Learning.

The LL database must be actively managed to ensure de-duplication, removal of out-ofdate material, and proactive problem resolution. Operation of an expert database and related CoPs are vital to the project learning process, where the sharing of experience provides the space for tacit knowledge to be expressed and converted to explicit knowledge. In developing learning capabilities for projects, it enables analysis of results 
to increase positives as well as reduce negatives, create best-practice activities, complete risk assessments, and analyse EWS and near-misses. Technical requirements for the IT system are not to be underestimated.

\section{Discussion}

The literature determined that LL were not being applied very well, and this appears to be substantiated by the data. However, the analysis also reveals that a significant minority of organisations are not identifying and capturing the LL through any formalised procedure, as recommended by the professional bodies. Hartmann and Dorée (2015) assert that separation of the LL process from the project environment is the problem, and the data confirms that little time or effort is given to post-project reporting, which is a significant factor. There is supporting evidence to demonstrate that personal experience and individual learning is taking place, albeit through informal methods.

The development of triple-loop learning to analyse the practical application of the lessonslearned process in organisations, identifies significant requirements for the industry. This theoretical contribution demonstrates how three levels of learning align with projects, by taking the research data and mapping it across the three project temporal phases (Figure 1). Viewed from the triple-loop perspectives of project, processes and the organisation (Figure 5), we present the nine requirements (Table 3) for our project learning framework. The actions from the planning stage also continue during the delivery stage in addition to those specifically shown, although omitted for clarity.

Table 3: Layering Lessons-Learned through Loops and Phases.

\section{Project Management Phases}

\section{Planning}

Delivery

Closure 


\begin{tabular}{|c|l|l|l|}
\hline $\begin{array}{c}\text { Single-Loop } \\
\text { Project }\end{array}$ & $\begin{array}{l}\bullet \text { access lessons } \\
\text { learned }\end{array}$ & $\begin{array}{l}\bullet \text { record new lessons } \\
\text { learned }\end{array}$ & $\bullet$ personal learning \\
\hline $\begin{array}{c}\text { Double-Loop } \\
\text { Process }\end{array}$ & $\begin{array}{c}\bullet \text { provide lessons } \\
\text { learned } \\
\text { provide expert }\end{array}$ & $\bullet$ support CoPs & $\bullet \begin{array}{l}\bullet \text { update lessons learned } \\
\text { revise expert list }\end{array}$ \\
\hline $\begin{array}{c}\text { Triple-Loop } \\
\text { Organisation }\end{array}$ & $\bullet$ set learning goals & $\begin{array}{l}\bullet \text { monitor projects } \\
\bullet \text { monitor learning }\end{array}$ & $\begin{array}{l}\bullet \text { define learning action } \\
\text { plans } \\
\text { update org goals }\end{array}$ \\
\hline
\end{tabular}

In section 4 we discussed how knowledge is subjective and dependent upon the perception of the individual, and that learning can be demonstrated by a change in behaviour due to experience. We now develop the triple-loop project learning process to identify those project and organisational learning activities that focus on the change of behaviour - the actions that should come from the LL. These learning activities are presented in Table 4.

Table 4: Triple-loop project learning activities.

\begin{tabular}{|c|c|c|c|}
\hline $\begin{array}{l}\text { Management } \\
\text { Domain } \\
\text { (where) }\end{array}$ & $\begin{array}{l}\text { Project Learning } \\
\text { Emphasis } \\
\text { (who) }\end{array}$ & $\begin{array}{l}\text { Project Benefits } \\
\text { Management } \\
\text { (what) }\end{array}$ & $\begin{array}{l}\text { Business Case Goals } \\
\text { (to what effect) }\end{array}$ \\
\hline $\begin{array}{l}\text { Single-loop } \\
\text { "Project" }\end{array}$ & $\begin{array}{l}\text { - Personal learning } \\
\text { through experience }\end{array}$ & $\begin{array}{l}\text { - Personal development } \\
\text { through targets } \\
\text { - Career development }\end{array}$ & - Project targets \\
\hline $\begin{array}{l}\text { Double-loop } \\
\text { "Process" }\end{array}$ & $\begin{array}{l}\text { Project learning } \\
\text { through process }\end{array}$ & $\begin{array}{l}\text { - Technical } \\
\text { improvements } \\
\text { - Process improvements }\end{array}$ & $\begin{array}{l}\text { - Project management } \\
\text { learning } \\
\text { - Team learning }\end{array}$ \\
\hline $\begin{array}{c}\text { Triple-loop } \\
\text { "Organisation" }\end{array}$ & $\begin{array}{l}\text { - Organisational } \\
\text { learning through } \\
\text { ethos }\end{array}$ & $\begin{array}{l}\text { - System development } \\
\text { - Appropriate } \\
\text { Governance }\end{array}$ & $\begin{array}{l}\text { - Organisational learning } \\
\text { goals } \\
\text { - Corporate values } \\
\text { - Alignment with Vision } \\
\text { \& Mission statement }\end{array}$ \\
\hline
\end{tabular}

Combining the three loops of project learning with the project learning activities, demonstrates that learning goals defined at all organisational levels should form part of the 
business case, project benefits, and risk management processes. The top reason for project failure according to the practicing project managers is poor pre-planning for the project. This accounted for 36 of the comments that included the following main points - "Too much optimism with estimating", "Lack of ability to manage the front-end very well", "Lack of clear requirements", "Under estimate the project cost, risks and duration", and "Not focussing on the benefits".

A learning organisation provides an enabling environment by creating a culture of continual improvement and development of its people, products and services from the top management down through the whole company. The PM research community now has a theoretical platform based on organisational learning and knowledge management, from which to develop a project learning maturity model. This unique combination of theory with demonstrable practical application addresses many of the issues found with previous theories and models on the lessons-learned topic.

\section{Future research}

The vital aspect of this research is to demonstrate the importance of learning through projects, and to ensure its focus within the BoKs of the main professional project organisations - APM and PMI. The inclusion of learning management within the BoK could be undertaken similarly to the current risk management sections, and the next phase of this research will propose such a framework. However, there is also a need for the generic tools and techniques to be developed to work in parallel with the BoKs which are the focus of a future research phase. 


\section{Acknowledgements}

The authors acknowledge the constructive feedback and suggestions from the three anonymous reviewers.

\section{Conflict of interest and funding}

The authors declare that there are no conflicts of interest regarding this paper. This research did not receive any specific grant from funding agencies in the public, commercial, or notfor-profit sectors.

\section{References}

Algeo, C., 2014. Exploring Project Knowledge Acquisition and Exchange Through Action Research. Proj. Manag. J. 45, 46-56. doi:10.1002/pmj.21417

Argyris, C., 1999. On Organizational Learning, 2nd ed. Blackwell Publishing, Oxford, UK.

Argyris, C., Schön, D.A., 1996. Organizational Learning II: Theory, Method, and Practice. Addison-Wesley Publishing Company, New York.

Association for Project Management, 2012. APM Body of Knowledge, 6th ed. Association for Project Management, Princes Risborough, UK.

Bakker, R.M., Cambré, B., Korlaar, L., Raab, J., 2011. Managing the project learning paradox: A set-theoretic approach toward project knowledge transfer. Int. J. Proj. Manag. 29, 494-503. doi:10.1016/j.ijproman.2010.06.002

Bartsch, V., Ebers, M., Maurer, I., 2013. Learning in project-based organizations: The role of project teams' social capital for overcoming barriers to learning. Int. J. Proj. Manag. 31, 239-251. doi:10.1016/j.ijproman.2012.06.009

Bateson, G., 2000. Steps to an ecology of mind. University of Chicago Press, Chicago.

Bredo, E., 1989. Bateson's Hierarchical Theory of Learning and Communication. Educ. Theory 39, 27-38. doi:10.1111/j.1741-5446.1989.00027.x

Caldwell, R., 2012. Leadership and Learning: A Critical Reexamination of Senge's Learning Organization. Syst. Pract. Action Res. 25, 39-55. doi:10.1007/s11213-0119201-0

Crossan, M.M., Lane, H.W., White, R.E., 1999. An Organizational Learning Framework: From Intuition to Institution. Acad. Manag. Rev. 24, 522-537. doi:10.5465/AMR.1999.2202135 
Desai, V., 2008. Constrained Growth: How Experience, Legitimacy, and Age Influence Risk Taking in Organizations. Organ. Sci. 19, 594-608. doi:10.1287/orsc.1070.0335

Dewey, J., 2005. The Copernican Revolution (1929), in: Capps, D., Capps, J.M. (Eds.), James and Dewey on Belief and Experience. University of Illinois Press, Champaign, IL, pp. 196-214.

Duffield, S., Whitty, S., 2015. Developing a systemic lessons learned knowledge model for organisational learning through projects. Int. J. Proj. Manag. 33, 311-324. doi:10.1016/j.ijproman.2014.07.004

Eden, C., Huxham, C., 2001. The Negotiation of Purpose in Multi-organizational Collaborative Groups. J. Manag. Stud. 38, 373-391.

Fillion, G., Koffi, V., Ekionea, J., 2015. Peter Senge's Learning Organization: A Critical View and the Addition of Some New Concepts to Actualize Theory and Practice. J. Organ. Cult. Commun. Confl. 19, 73-102.

Flyvbjerg, B., 2014. What You Should Know About Megaprojects and Why: An Overview. Proj. Manag. J. 45, 6-19. doi:10.1002/pmj.21409

Goffin, K., Koners, U., Baxter, D., van der Hoven, C., 2010. Managing lessons learned and tacit knowledge in new product development. Res. Technol. Manag. 53, 39-51.

Haji-Kazemi, S., Andersen, B., Klakegg, O.J., 2015. Barriers against effective responses to early warning signs in projects. Int. J. Proj. Manag. 33, 1068-1083. doi:10.1016/j.ijproman.2015.01.002

Haji-Kazemi, S., Andersen, B., Krane, H.P., 2013. A Review on Possible Approaches for Detecting Early Warning Signs in Projects. Proj. Manag. J. 44, 55-69. doi:10.1002/pmj.21360

Hall, P.A., 1993. Policy Paradigms , Social Learning, and the State: The Case of Economic Policymaking in Britain. Comp. Polit. 25, 275-296.

Hartmann, A., Dorée, A., 2015. Learning between projects: More than sending messages in bottles. Int. J. Proj. Manag. 33, 341-351. doi:10.1016/j.ijproman.2014.07.006

Hasan, H., Crawford, K., 2003. Codifying or enabling: the challenge of knowledge management systems. J. Oper. Res. Soc. 54, 184-193. doi:10.1057/palgrave.jors. 2601388

Huber, G.P., 1991. Organizational Learning: The Contributing Processes and the Literatures. Organ. Sci. 2, 88-115. doi:10.1287/orsc.2.1.88

Ika, L.A., Donnelly, J., 2017. Success conditions for international development capacity building projects. Int. J. Proj. Manag. 35, 44-63. doi:10.1016/j.ijproman.2016.10.005

Irani, Z., 2010. Investment evaluation within project management: an information systems perspective. J. Oper. Res. Soc. 61, 917-928. doi:10.1057/jors.2010.10

Isaacs, W.N., 1993. Taking flight: Dialogue, Collective Thinking, and Organizational Learning. Organ. Dyn. 22, 24-39. doi:10.1016/0090-2616(93)90051-2 
Jessop, A., Parker, D., Temple, J., 2016. Donor patterns: a modular structure for sharing knowledge. J. Oper. Res. Soc. 67, 378-392. doi:10.1057/jors.2015.31

Johnson, A.G., 2000. Knowledge, in: The Blackwell Dictionary of Sociology. Blackwell Publishers, Oxford, UK.

Jugdev, K., Wishart, P., 2014. Mutual Caring-Resolving Habituation Through Awareness: Supporting Meaningful Learning From Projects. Proj. Manag. J. 45, 66-82. doi:10.1002/pmj.21406

Klakegg, O.J., Williams, T., Walker, D., Andersen, B., Magnussen, O.M., 2010. Early Warning Signs in Complex Projects. Project Management Institute, Inc., Newtown Square, PA.

Labib, A., Read, M., 2013. Not just rearranging the deckchairs on the Titanic: Learning from failures through Risk and Reliability Analysis. Saf. Sci. 51, 397-413. doi:10.1016/j.ssci.2012.08.014

Langston, C., Ghanbaripour, A.N., 2016. A Management Maturity Model (MMM) for project-based organisational performance assessment. Constr. Econ. Build. 16, 68. doi:10.5130/AJCEB.v16i4.5028

Lepore, S.J., Revenson, T.A., 2006. Resilience and Posttraumatic Growth: Recovery, Resistance, and Reconfiguration, in: Calhoun, L.G., Tedeschi, R.G. (Eds.), Handbook of Posttraumatic Growth: Research and Practice. Lawrence Erlbaum Associates, Inc., New Jersey, pp. 24-46.

Lindner, F., Wald, A., 2011. Success factors of knowledge management in temporary organizations. Int. J. Proj. Manag. 29, 877-888. doi:10.1016/j.ijproman.2010.09.003

Meredith, J., Mantel, S.J., 2010. Project Management: A Managerial Approach, 7th ed. John Wiley and Sons, Inc., Hoboken, NJ.

Nonaka, I., Takeuchi, H., 1995. The Knowledge-Creating Company. Oxford University Press, Oxford, UK.

Nonaka, I., Toyama, R., Konno, N., 2000. SECI, Ba and Leadership: a Unified Model of Dynamic Knowledge Creation. Long Range Plann. 33, 5-34. doi:10.1016/S00246301(99)00115-6

Office of Government Commerce, 2009. Managing Successful Projects with PRINCE2, 5 th ed. TSO, London, UK.

Preskill, H., Torres, R., 1999. The Role of Evaluative Enquiry in Creating Learning Organizations, in: Easterby-Smith, M., Burgoyne, J., Araujo, L. (Eds.), Organizational Learning and the Learning Organization: Developments in Theory and Practice. Sage Publications Ltd, London, UK, pp. 92-114.

Probst, G., Buchel, B., 1997. Organizational Learning: The Competitive Advantage of the Future. Prentice Hall Europe, Hemel Hempstead, UK.

Project Management Institute, 2013. A Guide to the Project Management Body of Knowledge (PMBOK guide), 5th ed. Project Management Institute, Inc., Newtown Square, PA. 
Ranjbarfard, M., Aghdasi, M., López-Sáez, P., Emilio Navas López, J., 2014. The barriers of knowledge generation, storage, distribution and application that impede learning in gas and petroleum companies. J. Knowl. Manag. 18, 494-522. doi:10.1108/JKM08-2013-0324

Rolstadas, A., Tommelein, I., Morten Schiefloe, P., Ballard, G., 2014. Understanding project success through analysis of project management approach. Int. J. Manag. Proj. Bus. 7, 638-660. doi:10.1108/IJMPB-09-2013-0048

Senge, P., 2006. The Fifth Discipline: The Art \& Practice of The Learning Organisation. Random House, London, UK.

Tosey, P., Visser, M., Saunders, M., 2012. The origins and conceptualizations of "tripleloop" learning: A critical review. Manag. Learn. 43, 291-307. doi:10.1177/1350507611426239

Vaughan, D., 1996. The Challenger Launch Decision: Risky Technology, Culture, and Deviance at NASA. The University of Chicago Press, Chicago.

Walker, A., 2006. Learning, in: Salkind, N. (Ed.), Encyclopedia of Human Development. Sage Publications, Thousand Oaks, CA.

Wijnhoven, F., 2003. Operational knowledge management: identification of knowledge objects, operation methods, and goals and means for the support function. J. Oper. Res. Soc. 54, 194-203. doi:10.1057/palgrave.jors.2601393

Williams, T., 2016. Identifying Success Factors in Construction Projects: A Case Study. Proj. Manag. J. 47, 97-112. doi:10.1002/pmj.21558

Williams, T., 2003. Learning from projects. J. Oper. Res. Soc. 54, 443-451. doi:10.1057/palgrave.jors. 2601549

Zhao, D., Zuo, M., Deng, X., 2015. Examining the factors influencing cross-project knowledge transfer: An empirical study of IT services firms in China. Int. J. Proj. Manag. 33, 325-340. doi:10.1016/j.ijproman.2014.05.003 